\title{
Amir Raz
}

$\mathrm{P}$ ractitioners of pediatric medicine may still be undecided as to whether the newer generation of antidepressant drugs is effective for child and adolescent depression (CAD) [1]. Since 1989, when selective serotonin reuptake inhibitors (SSRIs) were introduced in the United States, they have become the top-selling drug category; as many as one in eight adult Americans having tried at least one SSRI in the past ten years. Despite their popularity in treating adult depression, the efficacy of SSRIs for CAD remains in dispute. In this article, I examine some of the core problems in medical research that have led to this disagreement.

\section{Specificity, Safety, and Efficacy}

Advances in molecular biology and neuroscience have fostered increasingly specific drugs. However, the pharmaceutical industry promotes an idea of drug specificity that may extend beyond the existing data. For example, SSRIs may selectively block the reuptake of serotonin, as claimed by many SSRI manufacturers, but they also influence numerous postsynaptic serotonin receptor systems, instigating multiple neurochemical effects.

Furthermore, certain neurotransmitter systems are so tightly entwined that affecting one inevitably influences others (e.g., selective norepinepherine reuptake inhibitors also influence the serotonergic system). Hence, drugs often have effects that seem unrelated to the presumed therapeutic outcome (e.g., tricyclic antidepressants [TCAs] and SSRIs have significant effects on fast sodium channels and platelet function, respectively). And one drug can treat a variety of syndromes.

The Policy Forum allows health policy makers around the world to discuss challenges and opportunities for improving health care in their societies.
For example, SSRIs are effective for symptoms ranging from obsessivecompulsive disorder to panic and anxiety. Thus, specificity, as defined by the pharmaceutical industry, is perhaps an overextended notion.

Antidepressant medications have become central to managing CAD [2]. Because double-blind trials of TCAs have failed to show greater efficacy than placebo for treating CAD [3,4], and concerns have been raised about the side effects of TCAs, SSRIs have been seen as the viable option for treating CAD [5]. Indeed, the 21st century ushered in major clinical guidelines endorsing SSRIs as firstline pharmacotherapy for CAD in both North America and the United

\section{The efficacy of SSRIs for child and adolescent depression remains in dispute.}

Kingdom [6,7]. Most rigorous studies that tested the safety and efficacy of these medications in depressed adolescents began after these drugs were deemed "first line" by the professional community of child and adolescent psychiatrists.

Yet the recent history of SSRIs is replete with inconsistent verdicts about their safety. For example, in January 2003, the US Food and Drug Administration (FDA) approved fluoxetine for children and adolescents. However, about five months later, concerns arose among psychiatrists about whether the drug was associated with suicidal thinking and behavior in children and adolescents. Nevertheless, in December 2003, the UK Medicines and Healthcare Products Regulatory Agency (MHRA) supported the use of fluoxetine in children and adolescents
$[8,9]$. It stated that for three other SSRIs (sertraline, citalopram, and escitalopram) the risks outweighed the benefits, while the balance of risks and benefits was "unassessable" for a fourth SSRI, fluvoxamine [8]. In September 2004, based on a review of 24 trials of nine different antidepressant drugs that were used to treat CAD, obsessive compulsive disorder, or "other psychiatric disorders," the FDA also supported the use of fluoxetine in treating CAD [10]. Prior to this, on March 22, 2004, the FDA had issued a "black box" warning label on all antidepressants, cautioning that these medications may "increase the risk of suicidal thinking and behavior (suicidality) in children and adolescents with major depressive disorder (MDD) and other psychiatric disorders" [11].

In its September 2004 review, the FDA endorsed SSRI safety as

Citation: Raz A (2006) Perspectives on the efficacy of antidepressants for child and adolescent depression. PLoS Med 3(1): e9.

Copyright: $\odot 2006$ Amir Raz. This is an open-access article distributed under the terms of the Creative Commons Attribution License, which permits unrestricted use, distribution, and reproduction in any medium, provided the original work is properly cited.

Abbreviations: $C A D$, child and adolescent depression; CBT, cognitive behavioral therapy; $\mathrm{Cl}$, confidence interval; FDA, Food and Drug Administration; MDD, major depressive disorder; MHRA, Medicines and Healthcare Products Regulatory Agency; $\mathrm{RCT}$, randomized clinical trial; SSRI, selective serotonin reuptake inhibitor;TADS, Treatment for Adolescents with Depression Study; TCA, tricyclic antidepressant

Amir Raz is in the Department of Psychiatry, Division of Child and Adolescent Psychiatry, Columbia University College of Physicians and Surgeons, New York, New York, United States of America, and at the New York State Psychiatric Institute, New York, New York, United States of America.E-mail:ar2241@ columbia.edu

Competing Interests: The author declares that he has no competing interests

DOI: 10.1371/journal.pmed.0030009 
Table 1. A List of Published and Unpublished Sources Commonly Cited in Recent Reviews Reporting on SSRIs for Child and Adolescent Depression

\begin{tabular}{|c|c|c|c|c|c|}
\hline Primary Data Source & & [52] & [53] & [50] & [55] \\
\hline \multirow[t]{8}{*}{ Published } & Fluoxetine [38] & $x$ & $x$ & & $x$ \\
\hline & Venlafaxine [94] & $X^{a}$ & $x$ & $x$ & $x$ \\
\hline & Fluoxetine [29] & $x$ & $x$ & $x$ & $x$ \\
\hline & (Paroxetine) [35] & $x$ & $x$ & $x$ & $x$ \\
\hline & (Fluoxetine) [30] & $x$ & $x$ & $x$ & $x$ \\
\hline & (Sertraline) $^{\mathrm{b}}$ [95] & $x$ & $x$ & $x$ & $x$ \\
\hline & (Citalopram) [54] & & & $X^{c}$ & $x$ \\
\hline & (Fluoxetine) [23] & & & & $x$ \\
\hline \multirow[t]{7}{*}{ Unpublished } & Citalopram & & & $x$ & $x$ \\
\hline & Paroxetine & & & $x$ & $x$ \\
\hline & Paroxetine & & & $x$ & $x$ \\
\hline & Venlafaxine & & & $x$ & $x$ \\
\hline & Venlafaxine & & & $x$ & $x$ \\
\hline & Nefazadone & & & & $x$ \\
\hline & Nefazadone & & & & $x$ \\
\hline
\end{tabular}

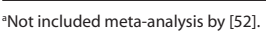

${ }^{\mathrm{b} T w o}$ separate trials analyzed and published together.

'Reviewed prior to publication (draft differed slightly from published paper).

This table is an updated version of Table 1 in [13]. Only the more recent studies account for unpublished data, which are important to the formulation of a comprehensive and informed opinion regarding drug efficacy and safety.

DOl: 10.1371/journal.pmed.0030009.to0

well as an arbitrary improvement criterion-some decrease, relative to placebo, on a reputable scale (e.g., a two-point drop on the Hamilton depression scale)—without addressing actual clinical efficacy. However, the resulting assumption among some practitioners was that SSRIs in general are effective, as well as safe, for CAD. This conclusion is consistent with recent reviews [12,13], drawing on both published and unpublished data, reporting that at least fluoxetine is seen as a safe and efficacious treatment for CAD. The tendency to embrace SSRIs for CAD demonstrates a trend in pediatric mental health practice toward taking efficacy for granted and focusing on safety.

\section{Statistical Significance versus Clinical Significance}

Paying too much attention to significance tests and too little attention to the analysis methods [14] or other aspects of the data (e.g., the estimates of the magnitude of the effects [15]) may blur the difference between statistical significance and clinical importance $[16,17]$. Furthermore, statistical significance itself can be clinically meaningless.

For example, a hypothetical study with a large sample size might show that an average heart rate of 69 on placebo compared to 71 on a drug is statistically significant, but this effect is likely to be clinically meaningless. In fact, the only standard for determining drug efficacy for "quality-of-life illnesses," including CAD, is a placebocontrolled trial; a comparator (i.e., a "horse-race," or "drug A versus drug B") trial typically boosts the drug effect (P. Roose, personal communication and [18]). (This is partly due to the fact that when people know that they are being treated with either a more or less potent medicine, drug response tends to be more vigorous than when they know that they may be on either an actual drug or a placebo). Finally, scientific experiments rarely control for variables known to influence drug response (e.g., expectation, suggestion, motivation, site location, and trial length) (P. Roose, unpublished data).

Clinical significance-a meaningful change in the symptomatic state or functioning of an individual patient-requires independent replication of results [19]. Different fields have different criteria for clinical significance. Additionally, the statistical method used to calculate clinical significance affects the estimates of meaningful change [14]. Indeed, some professional associations (e.g., the American Psychological Association) have deemed effect sizes and confidence intervals to be more meaningful measures than significance testing [20].

To determine clinical significance through "risk-benefit" analysis [21], one must weigh the potential benefit of improved symptomatology, accompanied by adverse side effects, against the risk of leaving the disease untreated. Trying to address the issue of clinical significance, researchers have considered such parameters as the number needed to treat (NNT), the number needed to harm, and the number needed to prevent [22]. In the case of depression and CAD, FDA approval of fluoxetine implies that the FDA considered the number needed to harm to be reasonable. But what is a good value for NNT? Ideally, it would be as close as possible to one (i.e., we need to treat only one person in order to see a desired effect in one person), but actually the NNT tends to be much higher than one [23], and it is unclear what range of values permits clinicians to conclude that a favorable benefit-torisk ratio exists.

In addition, the NNT must be interpreted by using a comparison group. For example, in a placebo controlled trial, NNT $=3$ means that on average one of three patients will derive specific benefit from the treatment above and beyond placebo, which is rarely used clinically. Thus, NNT may be more clinically meaningful as an active comparator than in relation to a placebo. The absence of clear criteria for clinical efficacy is probably partially responsible for interpretation of the same data as being both for [24] and against [25] the efficacy of a specific drug.

Lacking clear criteria for clinical significance, statistical significance is perhaps the most convenient substitute [26]. But researchers may pay too much attention to the results of significance tests, thereby overlooking clinical significance. Statistical significance may not be a sufficient criterion for recommending a drug [27]. In the case of adult antidepressants, FDA approval requires that two randomized clinical trials (RCTs) show that drug performance is at least two Hamiltonscale points better than a placebo; however, this arbitrary criterion does not signify clinical efficacy. In fact, it is unclear what criteria should be used to assess clinical significance. For example, how many studies are needed to convince a clinician that a drug is efficacious? Clinical significance relies on replication and probably requires a meta-analysis. 
Recent $[21,50]$ as well as future metaanalyses, including one currently under preparation by A. Drews, I. Kirsch, and D.O. Antonuccio entitled "A Meta-Analysis of Antidepressants Trials for Depressed Children: Small Benefits, Large Stakes", may further illuminate the efficacy of antidepressants for CAD.

\section{Belief Systems}

While strong opinions on either side of any controversy may appear extreme, it is important not to disregard these beliefs immediately. For example, on February 2, 2004, Irving Kirsch and David Antonuccio offered their testimony to the FDA on the efficacy of antidepressants for treating children with depression. At that time, only a dozen RCTs had examined the efficacy of antidepressants in CAD (four assessed SSRIs, seven assessed TCAs, and one assessed both SSRIs and TCAs) [28-38] (see sidebar). Eight of these RCTs failed to find any significant benefit of medication over placebo. While no TCA-placebo comparisons showed significant differences, four of the five SSRI-placebo RCTs (plus a fifth that included SSRIs and TCAs) claimed significant differences between drug and placebo, but only on clinicianrated, not patient-rated, measures.

Since either means or standard deviations were missing in $25 \%$ of these RCTs, only nine were amenable to meta-analytic scrutiny. When Kirsch and Antonuccio combined data from these nine studies for analysis, the placebo response was $87 \%$ of the drug response, $75 \%$ of the SSRI response, and $97 \%$ of the TCA response. These results seem to indicate that TCAs have no significant pharmacological effect on CAD. They concluded that the effect of SSRIs may be statistically significant, but possibly not clinically significant.

While some psychopharmacologists dismiss investigators such as Kirsch and Antonuccio as "outliers" or inherently biased against the drug industry, such "outlying" accounts should nevertheless be examined. Opinions on either side of this issue should be considered, especially in the absence of definitive data and facts.

\section{Market Forces}

In the US, the pharmaceutical industry, Congress, and advocacy groups are known to both lobby and contribute generously to the FDA and may partially inspire its decisions and policies (P. Roose, personal communication). The influence of the pharmaceutical industry permeates science [39], and evidence points to the increasing commercial impact of biomedical research on scientific reporting $[40,41]$. Indeed, industry funding for research tends to yield favorable reports concerning the tested drug [42]. For example, among the authors of original research papers, reviews, and letters to the editor that were supportive of the use of specific drugs, 96\% had financial relationships with the drugs' manufacturers, whereas for publications deemed neutral or critical, the figures were only $60 \%$ and $37 \%$, respectively $[43,44]$.

Further, since negative results are often discounted or not published $[45,46,47]$, the message conveyed to the popular press and the public is often positively skewed [48],

\section{Incentives for Conducting Pediatric Clinical Trials}

Giving pharmaceutical companies an incentive to conduct pediatric tests, Congress passed the FDA Modernization Act in November 1997. Section 111 of this "pediatric exclusivity" partnership act offered drug sponsors six months (sometimes up to a year) of additional market exclusivity if they conducted pediatric studies on drugs still under some exclusivity provision. Under the FDA Modernization Act, the pharmaceutical company could continue to set the market price, keeping generic forms of the drug off the market. The original act has since been revised and extended through 2007 under the Best Pharmaceuticals for Children Act, but concerns still linger regarding disproportionate profits accrued by drug companies from the six-month extension compared to the cost of clinical trials, and the absence of commitment by the companies to publish or make readily available the safety and efficacy results of these trials [92]. While it is easy to see why pharmaceutical companies are eager to conduct pediatric research (six-month worldwide exclusivity for fluoxetine, for example, is estimated to be worth about a billion dollars), clinicians and patients rarely have access to these findings [93]. emphasizing benefits over risks and predicting improbable breakthroughs [49]. This trend may create unrealistic expectations about scientific advances or products and may lead to inappropriate and expensive utilization patterns. However, commercial pressure is not the only source of ambitious interpretations; another is researchers who are eager to promote their latest findings. Thus, conflicts of interest in SSRI trials for treating CAD may potentially cloud results.

\section{Different Reviews Have Had Different Results}

Although most previous reviews have been partisan, a few have presented a balanced account $[1,50,51]$. The first, though least comprehensive, review of RCTs conducted on newer antidepressants for CAD examined six published studies, including studies on venlafaxine and three SSRIs: fluoxetine (three studies), sertraline (one study), and paroxetine (one study) [52]. In their limited meta-analysis, the authors used a random effects model to pool averaged, selected outcomes across the five SSRI studies. They found a small effect size of 0.26 (95\% confidence interval [CI], 0.13-0.40), which they described as equivalent to a three-tofour-point improvement on the revised children's depression rating scale (which ranges from 17 to 113). They concluded that a large benefit from newer antidepressant drugs is unlikely. Reviewing the same studies, another report judged the efficacy data to be inconclusive [53].

Since the above reviews [52,53] included in their analysis a negative study of fluoxetine which involved a small $(\mathrm{n}=30)$, clinically heterogeneous (mixed inpatients and outpatients) participant group [39], some later reviews opted to exclude this negative study from their analyses. For example, one study analyzed five of the six published papers addressed in the above-mentioned reviews [52,53], as well as data from six unpublished studies accessed through collaboration with the UK's MHRA [50]. These unpublished studies included two investigations of venlafaxine, paroxetine, and citalopram, respectively (one of the citalopram studies was subsequently published [54]). After extracting raw data for outcome measures, including remission, response 
to treatment, and depressive symptoms scores, the authors reanalyzed, and-where possible-meta-analyzed published and unpublished studies of each drug, using fixed-effects and random-effects models. The authors concluded that only fluoxetine had evidence of efficacy that was robust: across two published trials, fluoxetine was more likely than placebo to bring about remission (number needed to benefit 6; 95\% CI, 4-15), or a clinically meaningful response (number needed to benefit 5; 95\% CI, 4-13). The study did not draw on unpublished fluoxetine efficacy data.

The most recent systematic review of newer antidepressants for CAD to date [55] included all of the data previously reviewed $[50,52,53]$ as well as unpublished data regarding two RCTs of nefazodone, and the recently published Treatment for Adolescents with Depression Study (TADS) [23], which compared fluoxetine, placebo, and cognitive behavioral therapy (CBT) alone and in combination (see Table 1). After examining efficacy outcomes and the influence of methodology (site selection, study population, study design, and outcome measures) on those outcomes, the authors found that the more methodologically sound SSRI studies tended to have better outcomes. For example, in the TADS, $60.6 \%$ (95\% CI, $51 \%-70 \%)$ of adolescents responded to fluoxetine alone, as opposed to a $34.8(95 \%$ CI, $26 \%-44 \%)$ response rate for placebo. Based on these findings and no evidence of differences among these drugs in adult populations, the authors concluded that most newer antidepressants are likely effective, and that different results have been largely due to methodological differences in studies of CAD. They concluded, therefore, that at least fluoxetine is clinically effective for CAD.

\section{Methodologic Oversights in Published Studies}

The TADS concluded that "medical management of MDD with fluoxetine, including careful monitoring for adverse events, should be made widely available" [23]. However, some researchers disagree with this conclusion [25].

The TADS explores four experimental arms: placebo, fluoxetine, CBT, and CBT + fluoxetine. Some of these treatment groups were "blind" (i.e., participants were unaware of what treatment they were receiving, as in the case for placebo) while others were informed (as in the case for CBT). However, Table 2 shows the difficulty of interpreting a study that compares blinded and unblinded treatment groups (e.g., differences between treatment groups might be due to the varying influence of expectation). Thus, in the interpretation of the TADS findings, subtle methodological caveats go unrecognized.

Relative to other studies, CBT does not fare well compared to both placebo and fluoxetine in the TADS. However, other studies comparing antidepressants and CBT showed that both were moderately effective in relieving depression in adults [56]. Adult neuroimaging findings suggest that the two methods work by improving the functioning of different brain circuits: CBT operates on cortical areas related to attention and comprehension, including the anterior cingulate cortex, whereas antidepressants operate on subcortical areas. Applying the adult data to children, these exploratory imaging results may provide both a context for testing drugs against nonpharmacological therapy and a basis for considering how to treat or even prevent depression in those who are most susceptible [57].

Table 2. A Subtle Flaw in the TADS: Condition I versus Condition II

\begin{tabular}{llll}
\hline Condition I & Blind or Not Blind & Condition II & Blind or Not Blind \\
\hline Placebo & Blind & Fluoxetine & Blind \\
CBT & Not blind & Fluoxetine & Blind \\
CBT and Fluoxetine & Both not blind & Fluoxetine & Blind \\
CBT and Fluoxetine & Both not blind & Fluoxetine & Not blind
\end{tabular}

In the TADS [23], one of the better studies in the field, half the participants knew what treatment they were getting. The TADS treatment comparisons report differences between placebo (blind) versus fluoxetine (blind); CBT (not blind) versus fluoxetine (blind); and CBT plus fluoxetine (both not blind) versus fluoxetine (blind). It is difficult to interpret findings comparing a blind arm of an experiment with one that is not blind. Given that it is difficult to blind CBT [96], critical comparisons such as that of CBT plus fluoxetine versus fluoxetine (all not blind) were not included in the TADS study, although perhaps they should have been.

DOl: 10.1371/journal.pmed.0030009.t002

Despite being regarded as efficacious in adults, meta-analysis of published RCTs indicates that $75 \%$ of antidepressant response in adults is duplicated by placebo [58]. This initial meta-analysis was amply critiqued by Klein for multiple limitations [59]. However, follow-up analyses using a different data set taken from the FDA, to which Klein's objections do not apply, again reported that about $80 \%$ of the response to antidepressants in adults was duplicated in placebo control groups $[60,61]$. Together with the notion that antidepressant medication effects are typically weaker in children than adults $[58,60]$, these conclusions accord with earlier reviews that challenge the effects of antidepressants in CAD [4,62-67]. Merely labeling a pill an antidepressant does not make it so. In fact, the existing data suggest that antidepressants are probably more effective in treating anxiety than depression [68].

Another limitation draws on the implications of using antidepressants in early life [69]. Serotonin acts as a brain and glial growth factor in early development. Some serotonin receptors act during development to establish normal anxiety-like behavior later in life, while others play a role in synapse formation $[70,71]$. Some exploratory findings suggest that artificial perturbation of serotonin function in early life may alter the normal development of brain systems related to stress, motor development, and motor control $[71,72]$. Furthermore, early exposure to fluoxetine produced abnormal emotional behaviors in adult mice [69]. The critical role of serotonin in the maturation of brain systems that modulate emotional function in the adult suggests that, in concert with genetic makeup, low serotonin levels during early development may increase vulnerability to psychiatric disorders $[69,73]$. Early exposure to SSRIs, therefore, can potentially exact a heavy price in later life $[74,75]$.

These caveats suggest that, in addition to the potential implications of using antidepressants in early life, there are few compelling data sets, free of funding from drug companies, concerning the efficacy of antidepressant medications over and above their placebo value for CAD. These caveats also show the difficulty of assessing the clinical significance 
of the unique effects attributable to antidepressant medications. Because antidepressants work just slightly better than placebos, even according to data endorsed by the pharmaceutical industry, the image of antidepressants as more effective may be overreaching and perhaps a consequence of methodological artifacts [76].

\section{Public Health versus Individual Decisions}

The US Surgeon General makes decisions based on the greater good of a vast population: a mere twopoint improvement on the Hamilton depression scale may constitute a meaningful public-health benefit (D. Shaffer, unpublished data). However, parents decide whether their depressed adolescent child should receive CBT, fluoxetine, or start a vigorous exercise regime, based on an individually tailored risk-benefit analysis.

Most clinicians recommend psychotherapy for mild to moderate $\mathrm{CAD}$ and reserve SSRIs for severe

\section{Patients and physicians should demand stronger evidence for the efficacy of antidepressants.}

CAD or when therapy is not effective [21]. Yet given the large numbers of people suffering from depressive disorders (i.e., an estimated 1.5 million adolescents (12-18 years of age) with MDD in the US alone [77]), it is easy to see why offering therapy would be difficult (e.g., number of therapists and insurance considerations), thereby making the drug option more popular.

Despite early suggestions in the literature [78-80], accounts of the association between adult suicidality and the use of SSRIs have been inconclusive [81-83]. One early meta-analysis showed that SSRIs potentially decreased suicidal ideation as measured by a single question on the Hamilton depression score [83], but a more recent study reported a non-significant increase in suicide rates between patients assigned to SSRIs and those assigned to placebo or other antidepressants [82]. Despite the FDA's black-box label, some accounts suggest that since the introduction of SSRIs the number of successful suicides has steadily declined [84,85]. One recent meta-analysis reported that SSRIs increased the risk of suicide attempts, but not completions, across all indications [86]. Another, a metaanalysis of drug company data that were submitted to the MHRA's safety review, reported that SSRIs did not appear to increase the risk of suicide attempts or thoughts [87].

Data regarding SSRIs and youth suicide are sparser, but no less controversial $[12,13,88,89]$. One study reported an inverse relationship between regional change in use of antidepressants and suicide [90]. Nonetheless, the highest possible standard should be applied to scientific data involving drug treatment of children because they are essentially involuntary patients: when a medication is prescribed for a young child, the adult caregiver ensures that the child takes the medication, regardless of the child's own desires. Yet, studies of adolescent compliance with medication treatment report notoriously low compliance outside of the controlled settings of clinical trials.

The sparse RCT findings suggest that improvement may not always be clinically significant. When evaluating a medication with side effects, potential clinical implications for later life, and questionable effectiveness, it should be compared to interventions such as exercise and CBT, which have shown some therapeutic effects on depression without medical side effects and risks [91]. Originally celebrated but recently disparaged by modern psychiatry, therapeutic rapport may prove more clinically significant than drug specificity.

\section{Conclusions}

Given all of these limitations, patients and physicians should demand stronger evidence for the efficacy of antidepressants for CAD.

Some advocates assert that rather than using medication with side effects and low effectiveness, children should be offered interventions that produce therapeutic effects on depression without the medical side effects and associated risks [91]. However, clinicians and laypeople must apply comparable standards for evaluating the efficacy of drug and psychotherapy data. Whereas medical drug research occurs in a formally regulated, albeit imperfect, environment, safety and efficacy in psychotherapy research are largely unregulated. Moreover, unlike drug assays, psychotherapy studies do not typically report adverse events, their meta-analyses are sparse, and their experimental design lacks a placebo condition (see Table 2).

Finally, although antidepressants undoubtedly affect brain biochemistry, interpreting these neural changes is controversial, and a risk-benefit analysis of side effects and long-term health risks may cast a long shadow on the current preference for antidepressants as first-line treatment for CAD. Only more studies, and the passage of enough time to examine the putative long-term effects, will determine the efficacy of antidepressants in CAD. Clinicians, patients, families, and the public should be cognizant of these issues and exercise critical judgment as they make informed decisions.

\section{References}

1. Vitiello B, Swedo S (2004) Antidepressant medications in children. N Engl J Med 350: 1489-1491.

2. Wong IC, Besag FM, Santosh PJ, Murray ML (2004) Use of selective serotonin reuptake inhibitors in children and adolescents. Drug Saf 27: 991-1000.

3. Geller B, Reising D, Leonard HL, Riddle MA, Walsh BT (1999) Critical review of tricyclic antidepressant use in children and adolescents. J Am Acad Child Adolesc Psychiatry 38: 513516

4. Hazell P, O'Connell D, Heathcote D, Robertson J, Henry D (1995) Efficacy of tricyclic drugs in treating child and adolescent depression: A meta-analysis. BMJ 310: 897-901.

5. Emslie GJ, Walkup JT, Pliszka SR, Ernst M (1999) Nontricyclic antidepressants: Current trends in children and adolescents. J Am Acad Child Adolesc Psychiatry 38: 517-528.

6. Park RJ, Goodyer IM (2000) Clinical guidelines for depressive disorders in childhood and adolescence. Eur Child Adolesc Psychiatry 9: 147-161.

7. [Anonymous] (1998) Summary of the practice parameters for the assessment and treatment of children and adolescents with depressive disorders. J Am Acad Child Adolesc Psychiatry 37: 1234-1238.

8. United Kingdom Committee on Safety of Medicines, Medicines and Healthcare Products Regulatory Agency (2003) Use of selective serotonin reuptake inhibitors (SSRIs) in children and adolescents with major depressive disorder (MDD): Only fluoxetine (Prozac) shown to have a favourable balance of risks and benefits for the treatment of MDD in the under 18s. London: United Kingdom Committee on Safety of Medicines, Medicines and Healthcare Products Regulatory Agency. Available: http://www.focusproject.org.uk/ pooled/articles/BF_NEWSART/ view.asp?Q=BF_NEWSART_83376. Accessed 9 November 2005.

9. National Institute for Health and Clinical Excellence (2005) Depression in children: Identification and management of depression in children and young people in primary, community and secondary care. London: National Institute for Health and Clinical 
Excellence. Available: http://www.nice.org. uk/pdf/Depn_child_2ndcons_Fullguideline. pdf. Accessed 9 November 2005.

10. US Food and Drug Administration (2004 October 15) FDA launches a multi-pronged strategy to strengthen safeguards for children treated with antidepressant medications. Rockville (Maryland): Food and Drug Administration News. Available: http://www. fda.gov/bbs/topics/news/2004/NEW01124 html. Accessed 9 November 2005

11. Center for Drug Evaluation and Research, USFDA (2004 March 22) Worsening depression and suicidality in patients being treated with antidepressant medications. Rockville (Maryland): Food and Drug Administration. Available: http://www.fda.gov/cder/drug/ antidepressants/AntidepressanstPHA.htm. Accessed 9 November 2005.

12. Whittington CJ, Kendall T, Pilling S (2005) Are the SSRIs and atypical antidepressants safe and effective for children and adolescents? Curr Opin Psychiatry 18: 21-25.

13. Cheung A, Emslie GJ, Taryn ML (2004) Efficacy and safety of antidepressants in youth depression. J Can Acad Adolesc Psychiatry 13: 98-104.

14. Bauer S, Lambert MJ, Nielsen SL (2004) Clinical significance methods: A comparison of statistical techniques. J Pers Assess 82: 60-70.

15. Rutledge T, Loh C (2004) Effect sizes and statistical testing in the determination of clinical significance in behavioral medicine research. Ann Behav Med 27: 138-145.

16. Hojat M, Xu G (2004) A visitor's guide to effect sizes: Statistical significance versus practical (clinical) importance of research findings. Adv Health Sci Educ Theory Pract 9: 241-249.

17. Glaros AG (2004) Statistical and clinical significance: Alternative methods for understanding the importance of research findings. J Ir Dent Assoc 50: 128-131.

18. Roose SP, Sackeim HA (2002) Clinical trials in late-life depression: Revisited. Am J Geriatr Psychiatry 10: 503-505.

19. Bhardwaj SS, Camacho F, Derrow A, Fleischer AB Jr., Feldman SR (2004) Statistical significance and clinical relevance: The importance of power in clinical trials in dermatology. Arch Dermatol 140: 1520-1523.

20. Cohen J $(1990)$ The earth is round $(\mathrm{p}<.05)$. Am Psychol 49: 997-1003.

21. Haby MM, Tonge B, Littlefield L, Carter R, Vos T (2004) Cost-effectiveness of cognitive behavioural therapy and selective serotonin reuptake inhibitors for major depression in children and adolescents. Aust N Z J Psychiatry 38: 579-591

22. Laupacis A, Sackett DL, Roberts RS (1988) An assessment of clinically useful measures of the consequences of treatment. N Engl J Med 318 1728-1733.

23. (2005) The Treatment for Adolescents with Depression Study (TADS): Demographic and clinical characteristics. J Am Acad Child Adolesc Psychiatry 44: 28-40.

24. Carroll BJ (2004) Adolescents with depression. JAMA 292: 2578

25. Antonuccio D, Burns D (2004) Adolescents with depression. JAMA 292: 2577.

26. Gigerenzer G (1993) The superego, the ego, and the id in statistical reasoning. In: Keren $\mathrm{G}$, Lewis C, editors. A handbook for data analysis in the behavioral sciences: Methodological issues. Hillsdale (New Jersey): Erlbaum. pp. 311-339.

27. Killeen PR (2005) An alternative to nullhypothesis significance tests. Psychol Sci 16: 345-353.

28. Boulos C, Kutcher S, Marton P, Simeon J, Ferguson B, et al. (1991) Response to desipramine treatment in adolescent major depression. Psychopharmacol Bull 27: 59-65.

29. Emslie GJ, Rush AJ, Weinberg WA, Kowatch RA, Hughes CW, et al. (1997) A double- blind, randomized, placebo-controlled trial of fluoxetine in children and adolescents with depression. Arch Gen Psychiatry 54: 10311037

30. Emslie GJ, Heiligenstein JH, Wagner KD, Hoog SL, Ernest DE, et al. (2002) Fluoxetine for acute treatment of depression in children and adolescents: A placebo-controlled, randomized clinical trial. J Am Acad Child Adolesc Psychiatry 41: 1205-1215.

31. Geller B, Cooper TB, Graham DL, Marsteller FA, Bryant DM (1990) Double-blind placebocontrolled study of nortriptyline in depressed adolescents using a "fixed plasma level" design. Psychopharmacol Bull 26: 85-90.

32. Geller B, Cooper TB, Graham DL, Fetner HH, Marsteller FA, et al. (1992) Pharmacokinetically designed double-blind placebo-controlled study of nortriptyline in 6to 12-year-olds with major depressive disorder. J Am Acad Child Adolesc Psychiatry 31: 34-44.

33. Keller MB, Ryan ND, Strober M, Klein RG, Kutcher SP, et al. (2001) Efficacy of paroxetine in the treatment of adolescent major depression: A randomized, controlled trial. J Am Acad Child Adolesc Psychiatry 40: 762-772.

34. Kramer AD, Feiguine RJ (1981) Clinical effects of amitriptyline in adolescent depression. A pilot study. J Am Acad Child Psychiatry 20: 636-644.

35. Kutcher S, Boulos C, Ward B, Marton P, Simeon J, et al. (1994) Response to desipramine treatment in adolescent depression: A fixed-dose, placebo-controlled trial. J Am Acad Child Adolesc Psychiatry 33: 686-694.

36. Preskorn SH, Weller EB, Hughes CW, Weller RA, Bolte K (1987) Depression in prepubertal children: Dexamethasone nonsuppression predicts differential response to imipramine vs. placebo. Psychopharmacol Bull 23: 128-133.

37. Puig-Antich J, Perel JM, Lupatkin W, Chambers WJ, Tabrizi MA, et al. (1987) Imipramine in prepubertal major depressive disorders. Arch Gen Psychiatry 44: 81-89.

38. Simeon JG, Dinicola VF, Ferguson HB, Copping W (1990) Adolescent depression: A placebo-controlled fluoxetine treatment study and follow-up. Prog Neuropsychopharmacol Biol Psychiatry 14: 791-795.

39. Ferner RE (2005) The influence of big pharma. BMJ 330: 855-856.

40. Caulfield T (2004) The commercialisation of medical and scientific reporting. PLoS Medicine 1: e38. DOI: 10.1371/journal.pmed.0010038

41. Antonuccio DO, Danton WG, McClanahan TM (2003) Psychology in the prescription era: Building a firewall between marketing and science. Am Psychol 58: 1028-1043.

42. Bhandari M, Busse JW, Jackowski D, Montori VM, Schunemann H, et al. (2004) Association between industry funding and statistically significant pro-industry findings in medical and surgical randomized trials. CMAJ 170: 477-480.

43. Stelfox HT, Chua G, O'Rourke K, Detsky AS (1998) Conflict of interest in the debate over calcium-channel antagonists. N Engl J Med 338: 101-106.

44. van Kolfschooten F (2002) Conflicts of interest: Can you believe what you read? Nature 416 : 360-363.

45. Cassels A, Hughes MA, Cole C, Mintzes B, Lexchin J, et al. (2003) Drugs in the news: An analysis of Canadian newspaper coverage of new prescription drugs. CMAJ 168: 1133-1137.

46. Koren G, Klein N (1991) Bias against negative studies in newspaper reports of medical research. JAMA 266: 1824-1826.

47. Lenzer J (2005) Drug secrets: What the FDA isn't telling. Available: http://www.slate.com/ id/2126918. Accessed 1 November 2005

48. Bubela TM, Caulfield TA (2004) Do the print media "hype" genetic research? A comparison of newspaper stories and peer-reviewed research papers. CMAJ 170: 1399-1407.
49. Nelkin D (2001) Beyond risk. Reporting about genetics in the post-Asilomar press. Perspect Biol Med 44: 199-207.

50. Whittington CJ, Kendall T, Fonagy P, Cottrell D, Cotgrove A, et al. (2004) Selective serotonin reuptake inhibitors in childhood depression: Systematic review of published versus unpublished data. Lancet 363: 1341-1345.

51. National Institute for Health and Clinical Excellence (2005) Depression in children: Identification and management of depression in children and young people in primary, community and secondary care. Second draft for consultation. London: National Institute for Health and Clinical Excellence.

Available: http://www.nice.org.uk/pdf/

Scope_Depression_Child.pdf; http://www.nice. org.uk/pdf/Depn_child_2ndcons_\%20App_P. pdf. Accessed 15 November 2005.

52. Jureidini JN, Doecke CJ, Mansfield PR, Haby MM, Menkes DB, et al. (2004) Efficacy and safety of antidepressants for children and adolescents. BMJ 328: 879-883.

53. Courtney DB (2004) Selective serotonin reuptake inhibitor and venlafaxine use in children and adolescents with major depressive disorder: A systematic review of published randomized controlled trials. Can J Psychiatry 49: 557-563.

54. Wagner KD, Robb AS, Findling RL, Jin J, Gutierrez MM, et al. (2004) A randomized, placebo-controlled trial of citalopram for the treatment of major depression in children and adolescents. Am J Psychiatry 161: 1079-1083.

55. Cheung AH, Emslie GJ, Mayes TL (2005) Review of the efficacy and safety of antidepressants in youth depression. J Child Psychol Psychiatry 46: 735-754.

56. Mayberg HS (2003) Modulating dysfunctional limbic-cortical circuits in depression: Towards development of brain-based algorithms for diagnosis and optimised treatment. Br Med Bull 65: 193-207.

57. Posner MI, Rothbart MK (2005) Influencing brain networks: Implications for education. Trends Cogn Sci 9: 99-103.

58. Kirsch I, Sapirstein G (1998) Listening to Prozac but hearing placebo: A meta analysis of antidepressant medication. Prev Treat 1. Available: http://www.journals.apa.org/ prevention/volume1/pre0010002a.html. Accessed 9 November 2005.

59. Klein DF (1998) Listening to meta-analysis but hearing bias. Prev Treat 1. Available: http://www.journals.apa.org/prevention/ volume1/pre0010006c.html. Accessed 9 November 2005.

60. Kirsch I, Moore TJ, Scoboria A, Nicholls SS (2002) The emperor's new drugs: An analysis of antidepressant medication data submitted to the U.S. Food and Drug Administration. Prev Treat 5. Available: http://www.journals.apa. org/prevention/volume5/pre0050023a.html. Accessed 9 November 2005.

61. Moncrieff J, Kirsch I (2005) Efficacy of antidepressants in adults. BMJ 331: 155-157.

62. Dujovne VF, Barnard MU, Rapoff MA (1995) Pharmacological and cognitive-behavioral approaches in the treatment of childhood depression: A review and critique. Clin Psychol Rev 15: 589

63. Sommers-Flanagan J, Sommers-Flanagan R (1996) Efficacy of antidepressant medication with depressed youth: What psychologists should know. Prof Psychol Res Pr 27: 145-153.

64. Michael KD, Crowley SL (2002) How effective are treatments for child and adolescent depression? A meta-analytic review. Clin Psychol Rev 22: 247.

65. Kastelic EA, Labellarte MJ, Riddle MA (2000) Selective serotonin reuptake inhibitors for children and adolescents. Curr Psychiatry Rep 2: 117-123.

66. Ambrosini PJ, Bianchi MD, Rabinovich $\mathrm{H}$ Elia J (1993) Antidepressant treatments 
in children and adolescents. I. Affective disorders. J Am Acad Child Adolesc Psychiatry 32: 1-6.

67. Fisher RL, Fisher S (1996) Antidepressants for children. Is scientific support necessary? J Nerv Ment Dis 184: 99-102.

68. Schmitt R, Gazalle FK, Lima MS, Cunha A, Souza J, et al. (2005) The efficacy of antidepressants for generalized anxiety disorder: A systematic review and meta-analysis. Rev Bras Psiquiatr 27: 18-24.

69. Ansorge MS, Zhou M, Lira A, Hen R, Gingrich JA (2004) Early-life blockade of the 5-HT transporter alters emotional behavior in adult mice. Science 306: 879-881.

70. Hariri AR, Mattay VS, Tessitore A, Kolachana B, Fera F, et al. (2002) Serotonin transporter genetic variation and the response of the human amygdala. Science 297: 400-403.

71. Hariri AR, Drabant EM, Munoz KE, Kolachana BS, Mattay VS, et al. (2005) A susceptibility gene for affective disorders and the response of the human amygdala. Arch Gen Psychiatry 62: 146-152.

72. Casper RC, Fleisher BE, Lee-Ancajas JC, Gilles A, Gaylor E, et al. (2003) Follow-up of children of depressed mothers exposed or not exposed to antidepressant drugs during pregnancy. J Pediatr 142: 402-408.

73. Caspi A, Sugden K, Moffitt TE, Taylor A, Craig IW, et al. (2003) Influence of life stress on depression: Moderation by a polymorphism in the 5-HTT gene. Science 301: 386-389.

74. Coyle JT (1997) Biochemical development of the brain: Neurotransmitters and child psychiatry. In: Popper C, editor. Psychiatric pharmacosciences of children and adolescents. Washington (District of Columbia): American Psychiatric Press. pp. 3-25.

75. Coyle JT (2000) Psychotropic drug use in very young children. JAMA 283: 1059-1060.
76. Moncrieff J (2002) The antidepressant debate. Br J Psychiatry 180: 193-194.

77. Rifkin A, Rifkin W (2004) Adolescents with depression. JAMA 292: 2577-2578.

78. Masand P, Gupta S, Dewan M (1991) Suicidal ideation related to fluoxetine treatment. N Engl J Med 324: 420

79. Rothschild AJ, Locke CA (1991) Reexposure to fluoxetine after serious suicide attempts by three patients: The role of akathisia. J Clin Psychiatry 52: 491-493.

80. Teicher MH, Glod C, Cole JO (1990) Emergence of intense suicidal preoccupation during fluoxetine treatment. Am J Psychiatry 147: 207-210.

81. Jick H, Kave JA, Jick SS (2004) Antidepressants and the risk of suicidal behaviors. JAMA 292: 338-343.

82. Khan A, Khan S, Kolts R, Brown WA (2003) Suicide rates in clinical trials of SSRIs, other antidepressants, and placebo: Analysis of FDA reports. Am J Psychiatry 160: 790-792.

83. Baldwin D, Bullock T, Montgomery D, Montgomery S (1991) 5-HT reuptake inhibitors, tricyclic antidepressants and suicidal behaviour. Int Clin Psychopharmacol 6 (Suppl 3): 49-55.

84. Grunebaum MF, Ellis SP, Li S, Oquendo MA, Mann JJ (2004) Antidepressants and suicide risk in the United States, 1985-1999. J Clin Psychiatry 65: 1456-1462.

85. Healy D, Whitaker C (2003) Antidepressants and suicide: Risk-benefit conundrums. J Psychiatry Neurosci 28: 331-337.

86. Fergusson D, Doucette S, Glass KC, Shapiro S, Healy D, et al. (2005) Association between suicide attempts and selective serotonin reuptake inhibitors: Systematic review of randomised controlled trials. BMJ 330: 396.

87. Gunnell D, Saperia J, Ashby D (2005) Selective serotonin reuptake inhibitors (SSRIs) and suicide in adults: Meta-analysis of drug company data from placebo controlled, randomised controlled trials submitted to the MHRA's safety review. BMJ 330: 385.

88. Caballero J, Nahata MC (2005) Selective serotonin-reuptake inhibitors and suicidal ideation and behavior in children. Am J Health Syst Pharm 62: 864-867.

89. Licinio J, Wong ML (2005) Depression, antidepressants and suicidality: A critical appraisal. Nat Rev Drug Discov 4: 165-171.

90. Olfson M, Shaffer D, Marcus SC, Greenberg T (2003) Relationship between antidepressant medication treatment and suicide in adolescents. Arch Gen Psychiatry 60: 978-982.

91. Clarke GN, Rohde P, Lewinsohn PM, Hops H, Seeley JR (1999) Cognitive-behavioral treatment of adolescent depression: Efficacy of acute group treatment and booster sessions. J Am Acad Child Adolesc Psychiatry 38: 272-279.

92. [Anonymous] (2004 July 26) Waxman wants release of study summaries. Washington Drug Letter. Available: http://www.fdanews.com/ wdl/36_29/capitolhill/27380-1.html. Accessed 2 November 2005

93. [Anonymous] (2004 July 21) Waxman wants withheld data on pediatric depressants. Drug Industry Daily Online. Available: http://www. fdanews.com/did/3_141/capitolhill/ 27248-1.html. Accessed 2 November 2005

94. Mandoki MW, Tapia MR, Tapia MA, Sumner GS, Parker JL (1997) Venlafaxine in the treatment of children and adolescents with major depression. Psychopharmacol Bull 33: 149-154.

95. Wagner KD, Ambrosini P, Rynn M, Wohlberg C, Yang R, et al. (2003) Efficacy of sertraline in the treatment of children and adolescents with major depressive disorder: Two randomized controlled trials. JAMA 290: 1033-1041.

96. Kirsch I (2005) Placebo psychotherapy: Synonym or oxymoron? J Clin Psychol 61: 791-803.

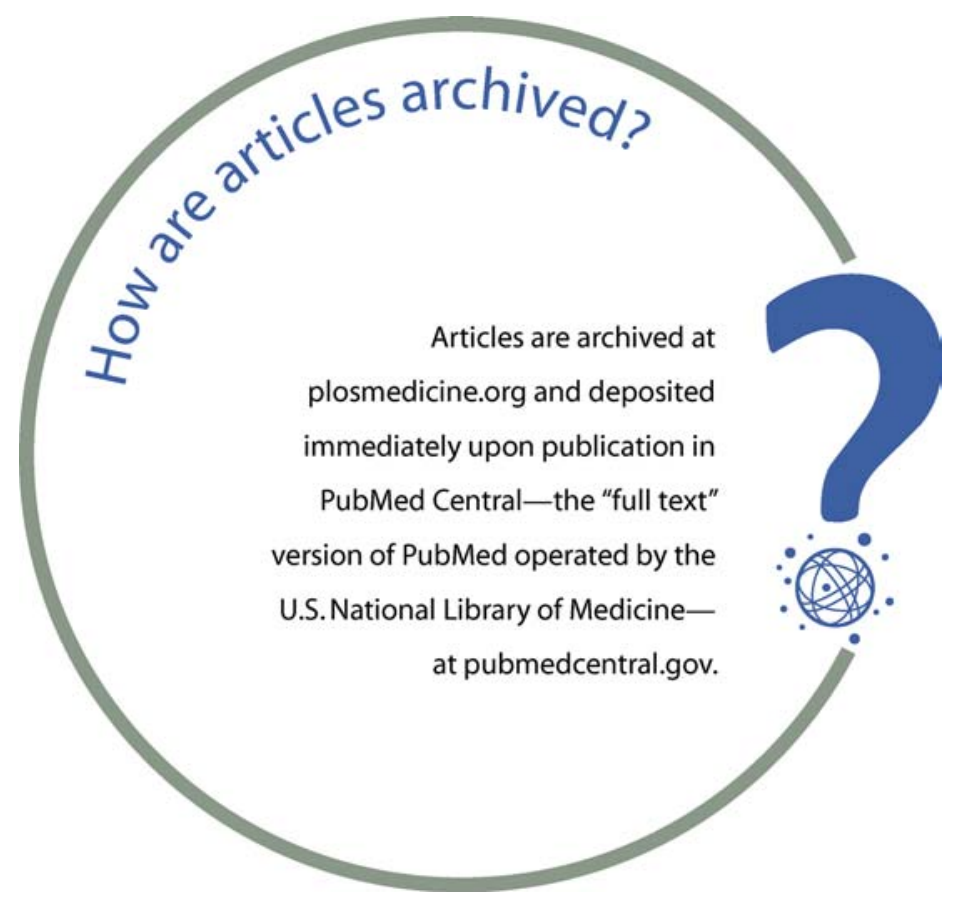

